\title{
Keeping it in the family: narrative maps of ageing and young athletes' perceptions of their futures
}

\author{
CASSANDRA PHOENIX* and ANDREW C. SPARKES*
}

\begin{abstract}
Drawing upon interviews with 22 young athletes aged on average 20 years, this article examines the ways in which they used observations of the ageing and old age of their family members to shape the ways in which they anticipated the ageing of their own bodies. The representations of the bodies, roles and lifestyles of their parents and grandparents provided 'narrative maps' that held pre-presentations of the young athletes' possible futures. They included both preferred and feared scenarios about middle age and old age, particularly the opportunities they would have for maintaining physical activity and the appearance of their bodies. The young men's and the young women's narrative maps differed: the women's accounts of old age gave more prominence to the loss of appearance, while the men's focused more on the loss of control and independence. The informants were highly sensitised to the biological dimensions of ageing which, for them, meant the inevitable decline of the material body, especially in performance terms, and both genders recognised social dimensions, particularly that responsibilities to jobs and family would constrain the time available for exercise. To understand more fully young athletes' experiences of self-ageing, and the family as a key arena for the embodied projection and inscription of ageing narratives, further research is required.
\end{abstract}

$\boldsymbol{K E Y} \boldsymbol{W O R D S}$ - inter-generational family relationships, narrative maps, possible selves, gender, body, young athletes, self-ageing.

\section{Introduction}

In recent years, social gerontology's long established interest in intergenerational relationships has elaborated, with studies of new dimensions of emotional support and care-giving (Shenk 200I; Schroder-Butterfill 2004; Hequembourg and Brallier 2005), of the impacts of divorce and separation (Bornat et al. 2000), and of changing roles within the family (Hyde and Gibbs r993; Jeffreys r997; Wenger and Burholt 200i; Drew

* School of Sport and Health Sciences, University of Exeter, UK. 
and Silverstein 2004). These and other recent studies have confirmed the importance of inter-generational relationships in family life, and shown that people's family experiences have significant consequences for how people understand and deal with ageing. Hockey and James (2003) emphasised that the family, the primary site of socialisation, is the key arena in which we come to know who we are, and who we can become as we age. By extension, observations of the ageing bodies of family members influence people's understanding of what it is like to be old, and structure the ways in which both individuals and social groups recognise old age in others and in themselves (Featherstone and Wernick r995). This point was elaborated by Sheehan and Donorfio (1999) who, from a study of older mothers and their care-giving daughters, suggested that inter-generational family relationships raise age awareness, prompt many mothers to begin to think of themselves as 'old', and lead daughters to begin to understand their own selves as someday being 'old'. Young people's contacts with different older people and their ageing bodies therefore shape their views of what they could or are likely to become.

Sheehan and Donorfio (I999: i68) saw that this process could have negative consequences: 'as daughters view their mothers' decline, they perceive ageing as a frightening experience'. Ex and Janssens (2000) studied young women's images of motherhood and closely examined the inter-generational transmission. Noting that there are same-sex dimensions of socialisation at adolescence between parent and child, they suggested that mothers were objects of identification and significant role models for their daughters. Many of the images that young women foresee for themselves can be related to their mother's appearance and functioning. In this sense, older same-sex family members are significant comparators, and influence a young person's anticipation of whether their own experience will challenge or confirm the negative stereotypes of old age that currently dominate western views of human ageing. This raises several important issues about the gendered nature of ageing and the ways in which the social meanings associated with the ageing male or female body are reproduced through same-sex inter-generational relationships.

Family relationships may therefore provide young people with prepresentations of what awaits them as they age, and a young person may perceive the bodies of their older relatives as indications of their own aged body. Most research on inter-generational family relationships has focused upon the experiences and outcomes for the older members, and currently there is little understanding of the ways in which these relationships influence young adults' perceptions of their own ageing bodies and of old age. Indeed, this limited understanding reflects the general absence of 
young bodies in the social gerontology literature. As many people are likely to develop an understanding of what it means to 'grow old' while they are still young, this is an important gap. Öberg (2003) suggested that young people do not look forward to growing old and are worried about future changes in their bodies. Likewise, Neikrug (2003: 327) noted that, 'worry about the loss of youth and the advance-of-years plagues many persons who are chronologically distant from old age'. In contemporary western societies, this may be especially so among women, who according to Furman (1997), are evaluated by others and by themselves against ideals of youthful attractiveness.

From the few studies conducted to date, it appears that growing old is viewed negatively by young people. Such narrow and negative interpretations of the ageing process might have implications for their own ageing and ultimately influence how they relate to older people. As Hodgetts, Chamberlain and Bassett (2003) argued, so long as youthfulness is valued more highly than being old, aged bodies will continue to be ridiculed and marginalised. Neikrug (2003: 327) also saw connections between negative perceptions of self-ageing and negative attitudes towards older people, and suggested that, 'for younger individuals, internalised negative stereotypes of ageing can support ageist attitudes, affect their relationships with older persons in their lives as well as causing worry about their own future'. Given the pervasiveness of these attitudes, exploring young people's perceptions of self-ageing may be a fruitful avenue of research for developing our understanding of the experience of personal ageing across the lifecourse.

The second important gap in the social gerontology literature addressed in this paper is the experience of the body (both biological and social) as it ages and changes over the life-course. Faircloth's (2003: I) view was that the topic 'lags behind' others in the field, and Twigg (2004: 59) recently argued that, while sociologists have recently become more interested in the systematic study of the body, '[its] presence in social gerontology has been more muted and uncertain'. This echoes Laz (2003: 504), who drew attention to the historical 'absent-presence' of bodies in the social sciences in general and social gerontology in particular, and argued that it is important that we 'understand and theorize the ways in which bodies are discursive - shaped, represented, and constructed - and appreciate the phenomenological experience of humans as organic creatures'. For Laz, such understanding and theorising should be with bodies in the sense of their fleshy physicality - skin, tissue, blood and genes. Furthermore, she contended that embodiment is a vital feature of the 'landscape of age', because age and embodiment are mutually constituted: 'there is no denying embodiment.... We are not 
the same - in corporeal terms - at 20 as at five, nor at 60 as at 20 [yearsof-age]' (2003: 518).

With these points in mind, numerous authors have argued that our understanding should move beyond the irresolvable debate about the relative importance of 'biology' and 'social identity' in the experience of ageing, and that this will be achieved by taking into consideration both the biological and social bodies in the unified 'embodied identity'. For example, Shilling (2003: 88) saw the body "as "unfinished" at birth, an entity which changes and develops throughout an individual's life', and argued that culture is the context in which the 'finishing' proceeds. Likewise, Hockey and James (2003: 122) argued that, 'though conception, gestation, birth, development and ageing are indeed "biological" processes, they are also fundamentally social affairs in that they involve the embodied interactions of individuals'. They remind us that while growing old will undoubtedly bring about physical changes in the biological body, such as greying hair, sagging skin, and hearing and sight losses, 'the ways in which these changes occur - how they are managed, interpreted and socially classified, what meanings they convey and what consequences they have for the individual - vary across and between societies' (2003: 123). Corporeality is itself therefore intrinsically social, and for Williams (2003), raising the understanding of embodiment in social gerontology will draw attention to and help redress the limitations of sociological scholarship. Along with Newton (2003), Williams also believed that a focus on embodiment and growing old might lead to useful new understanding of the relations between the biological and social determinants, between nature and culture, particularly at a time when the boundaries between the two have been blurred by technological developments, and that it would usefully promote the re-examination of our notions of identity and agency, and of experience and expression, as they develop through the lifecourse.

This study is a contribution to rectifying these gaps in social gerontology understanding. It focuses on young athletes and their attitudes towards their ageing bodies and future selves. To sustain their identity as an athlete, a young person has to invest heavily in their physical fitness, and they ascribe great psychological significance to the development and maintenance of a pain-free, strong, agile, productive, disciplined, toned and healthy body. Over time, however, the athletic body becomes increasingly difficult to maintain, because of the 'biological' processes of ageing. As Neikrug (2003) has pointed out, the professional athlete and others who depend on the attributes of youth for their livelihood may become 'old', or see themselves as 'old', long before they reach middle age. Indeed, by their late twenties or early thirties, many athletes find that sustaining 
their former physical condition - muscle tone, strength, agility, speed and power-becomes increasingly difficult. For this reason, involvement in competitive sports provides many experiences of ageing in early adulthood. More than that, maintaining the athletic body over time can be problematic for social as well as biological reasons. As young athletes move from full-time education to work and careers, many find that the time and facilities for the disciplined and repetitive training regimes they require to maintain their physical condition and performance are progressively restricted.

This paper examines how a group of young athletes perceived their own ageing. It is particularly concerned with the ways in which perceptions of self-ageing are shaped contextually and socially through involvement in sport, and by the 'signs and signals' about growing old that they perceive within their families. It draws on data from a larger project that explored young athletes' perceptions of self-ageing (Phoenix, Faulkner and Sparkes 2005; Phoenix and Sparkes 2006a), and particularly considers the messages that (grand) parents offer to their (grand) children about the ageing process.

\section{The primary research}

\section{Methods and the sample}

The study was of a purposeful sample of 22 young athletes, nine men and I3 women with an average age of 20 years, who were enrolled for a B.Sc. in Exercise and Sport Sciences at a university in England. They defined themselves as athletes and participated competitively in either team (I5) or individual (7) sports. Their standards of performance varied from international competition (7) to representing English regions (5) or the university (Io). They each took part in a series of confidential, informal, semi-structured, life-history interviews conducted by the primary investigator $[\mathrm{CP}]$. Each participant was interviewed between one and three times, each for between one and two hours. All interviews were taperecorded, transcribed, and subjected to a structural analysis and a content analysis (Lieblich, Tuval-Mashiach and Zilber i998). The former analysis focused on the formal plot and organisation of the narrative, to tease out the distinct structures that identified a particular narrative type. In contrast, the latter identified the central themes, typologies or instances of paradigmatic categories in the narratives. The themes and the concepts that they expressed emerged from the narrative data. Similarities in the participants' expressions were identified, categories defined, and relationships among the categories examined. 


\section{Analytical frameworks}

The analysis of the data was informed by several theoretical frames, one of which derived from Pollner and Stein's (1996) work on narrative maps. As they explained, 'through passage to a new status or a new social world, persons may find themselves on the threshold of uncharted territory whose customs, contours, and inhabitants are unknown' (1996: 203). They argued that when people contemplate an unfamiliar world beyond the here and now, they refer to knowledgeable or experienced others for orientation, information and advice about the psychosocial and physical landscape that awaits them. In these situations, personal experience is the sole source of authenticity, and the only way that one can truly understand the ageing experience is through 'having been there'. Narrative maps of ageing therefore have to be conveyed by, and learned from, those who have already traversed the territory (Holstein and Gubrium 2000: I83).

In this formulation, relationships with members of other generations whose bodies have already aged provide young adults with narrative maps that describe and advise them about the attributes, behaviour and problems they might encounter as they grow older. Pollner and Stein (I996: 219) argued that narrative maps 'may increase or reduce anxiety, motivation, and morale depending, of course, on what is portrayed as awaiting the traveller'. Furthermore, they shape the actions of those who draw upon them, by directing them towards certain states and activities and away from others, and by specifying the preparations necessary to attain their preferred future. By portraying the ageing process in positive or negative terms, they can also reinforce or challenge cultural stereotypes of ageing. Quite simply, narrative maps of ageing can influence how young people see the future.

The idea that narratives have the potential to shape individual action has been well documented. In their work on narrative and self, Gergen and Gergen (1988) pointed out that all life events were made socially visible through narratives, and that they were typically used to establish a person's expectations of future events. They argued further that narratives were socially-derived and sustained, and served as vehicles for comprehending the self, to the extent that, "we live by stories - both in the telling and doing of the self' (1988: 18). More recently, in a contribution on the relationship between narrative and self over the lifecourse, McAdams (I996) suggested that, for better or worse, the stories made and told by adults deeply influenced the stories and lives that others made.

Individuals' stories give rise in turn to others, in a continuous process of individual and cultural transmission and evolution. Furthermore, McAdams, like Gergen and Gergen (1988) and Pollner and Stein (1996), 
suggested that, by influencing the stories and lives of people, narrative has the potential to shape the type of self that one is now and that one might become. Thus, narrative maps formed by others' experiences and situations may encourage the development and utilisation of what Markus and Nurius (I986) termed 'possible selves', in other words, they contain the source of pre-presentations of what they might become. Possible selves include both what individuals would like to become (preferred selves), and what they are afraid of becoming (feared selves). While different and separable from present selves, 'possible selves' are intimately bound up with the present self through current hopes, fears and fantasies. Furthermore, while 'possible selves' are individual, they are also distinctly social; indeed, many result from social comparisons by which an individual's thoughts, feelings, characteristics and behaviours are contrasted with those of significant others. That is, 'what others are now, I could become' (Ig86: 954).

Having outlined the theoretical perspectives and analytical frameworks that have informed this study, we proceed to interpret the narrative maps of ageing that the 22 young athletes gathered from their parents and grandparents. We examine how these embodied pre-presentations of the ageing process portrayed both biological and social aspects of growing older, projected certain future selves as most likely, and ultimately contributed to the ways in which the participants anticipated the future.

\section{Young athletes' perceptions of the future}

Reflecting the dominance of the decline narrative of ageing in western societies, the structural analysis of the participants' perceptions of selfageing revealed that all spoke predominantly of bodily decline and deterioration. In addition, although none were actually 'middle-aged' or 'old', the content analysis illustrated that, when asked to describe how they imagined themselves in the future, each participant offered rich accounts of these stages of life by referring to the experiences of older family members. In particular, parents offered narrative maps about 'middle age', while grandparents provided narrative maps of 'old age'. The analysis also revealed the gendered nature of the narrative maps and the significance of same-sex relatives in shaping the young athletes' self-ageing stories.

\section{Parents and narrative maps of middle age}

When asked 'what does the term "middle age" mean to you?', all the participants at some point drew upon narrative maps of their parents. 
Faye, aged 2I years, who trained and competed with the university netball second team, replied:

I think it's quite difficult because I think when you're that kind of age [middle age], just going on my mum anyway, she was never sort of bothered about herself. She was more bothered about us and sort of running the family and taking us kids wherever we wanted to be taken. So that seems to be the focus of your life then. Obviously you've got your job, but it seems to be just family life. It will probably be like that for me as well.

Similarly, Matthew, aged i9 years, in the first year of the degree and a member of the university men's hockey club, commented:

I'm not looking forward to it. It's kind of, I don't know ... middle age just seems like hard work, especially for my mum. Trying to bring up two kids and going to work, coming home, going shopping, getting the food on the table. I mean sometimes she'd go out to aerobics or go to see a friend; she's all over the place really. She's always doing things and it just seems like a lot of hard work for her.

As these examples demonstrate, the narrative maps of their middle-aged parents provided the athletes with pre-representations of their own middle age, including the lifestyle that they might take up. All the participants saw middle age as a hectic time of life and as 'hard work', and as a life stage to which they rarely 'looked forward', not least because of the implications for their involvement in physical activity and, in turn, for their athletic bodies. More specifically, they expected middle age to bring a decrease in their level of physical activity, and the prospect had no attraction.

\section{Gendered stories in the perceptions of middle age}

There were interesting gender differences in the narrative maps of the young athletes: the women drew mainly upon the narrative maps offered by their mothers, and the men from their fathers'. Neil had played hockey since secondary school, and at the time of interview, when aged 2I years, competed with the university men's first team. In addition to the required four training sessions each week, he played for the city's hockey club: altogether he trained or competed eight times a week. When asked how physically active he thought he would be in middle age, he drew upon his father's experiences:

I'm kind of using dad as an example. I can see me generally not doing too much physical activity during the week, maybe play something like squash or badminton one or two nights a week and, at the weekend, doing the majority of my activity then. I'll hopefully still be playing hockey, and probably umpiring or coaching or something like that, but not nearly as much as now. The reason for that is probably a combination of being less physically able to do that, and 
also just the time constraints. At the moment, I've got time to train every day and as much as I want. ... I'm not looking forward to it [middle age], particularly not being able to train whenever I want to.

His comments echoed those of other male participants, who all anticipated a change in their routine of physical activity. In the present, the young male athletes were able to train 'every day' and 'as much as they wanted', but they believed that in middle age it would become increasingly difficult to maintain their athletic bodies through physical activity, both because of physiological decline ('being less physically able') and because of social pressures on their time ('the time constraints'). In this scenario, they anticipated that in middle age the time available for physical activity would be constricted but still available at weekends. Possibly because of this, the young male athletes made few references to anticipated changes in the appearance of their bodies. Gary, aged 2i years, who played for the university rugby second team and aspired to play for the first team, commented:

In middle age I expect I'll be settled into a job ... and still be involved in rugby, perhaps in a coaching capacity at the weekend or something. I'll probably be a wee bit heavier, looking at my dad; I mean he hasn't lost his hair or anything, so I think I'll probably be a more lived version of what I am now. But I don't think - from seeing my dad anyway - I don't think I'm going to change too much physically, and I'll still be keeping fit and stuff.

In great contrast, the female participants primarily drew upon narrative maps of ageing and middle age from their mothers, and these presented a different 'reality' for middle age. For example, Lynne, a I9-year-old swimmer, had previously competed at the national level and was a member of the university swimming squad, and exemplified the young women's thoughts about how physically active she would be in middle age:

I suppose when you have families and stuff, you do put on a lot of weight because you don't have time to do any exercise. My mum did, and she says that it's mainly since having me and my sister. I mean, I'd like to think that, after having kids, I could actually go to the gym and work on it [the body], so that you got your figure back. ... You're just not as active, I don't see my mum or anyone that much older than me being as active as I am now, so obviously something's going to change, unfortunately.

In describing how she foresaw her middle age, Lynne drew upon the experiences of her mother who had 'been there'. Lynne's comments anticipated much reduced physical activity, not just it being a question of re-scheduling to the weekends, but primarily because 'you don't have time'. This aspect of social ageing, i.e. acquiring time-consuming responsibilities, coupled with age-related changes to the biological body, especially through 
the birth of children, was anticipated as having negative implications for the future appearance of her body. Pamela, a 20-year-old second-year student who swam competitively for her home county, also commented on the consequences of reduced physical activity in middle age:

If I'm not swimming four times a week and going to the gym every other day, I can't expect to stay the same shape. So, yeah, I just think muscle tone and definition and stuff like that is just going to go.... You're not going to be the same person that you were before; you've got to realise that there are going to be changes, and I guess you just have to live with that. I know my mum's not happy with her body: she's joined weight-watchers and stuff, and she's doing well, but the weight never seems to stay off long-term.

Maintaining the appearance of their bodies was an important issue for the young women. Specifically, remaining physically active in middle age, which for some involved 'getting your figure back' following the birth of children, was central to their preferred selves. Upton and Han (2003) produced similar evidence, and pointed out that for many women, 'getting the body back' following childbirth signifies a struggle to reassert and regain particular identities and control over the body, and is therefore paramount. The young women's expressions (unlike the men's) featured a contradiction between their preferred future self and the narrative maps of their mothers' ageing; a difference between what the female participants would like to do (i.e. maintain an active, athletic self) and their perception of the reality of middle age (i.e. an inactive, non-athletic self). The tension was also mentioned by Vicky, the only first-year student to play for the university ladies' hockey first team:

I may one day have children and they always take a priority away from sport, so that would obviously affect me if I did have children; more so for girls than boys, I think, because guys carry on - don't they? - with their sport. ... My mum used to ride [horses] when she was younger, but then once she knew she was having kids, she stopped. I think she lost her nerve, but she's never really done anything else in its place. Sometimes she goes swimming, but it just seems that having kids definitely prioritises over sport, and then of course, your body isn't going to be what it was, it's not going to be that perfect or wonderful. But I still think it will be important to be active and healthy, to feel good about myself, not to be hung up on ... cosmetic-type things but ... to feel good about my body, the bodyshape and stuff. That will always be important, although I'm not sure how at 30 I'll feel - I don't know. Maybe I won't be bothered at all about my body when I'm 3o. I find it really difficult to look ahead and see how I'll be. But I think looking at my mum - I think I'll always be quite image-conscious. She is, especially now her skin's starting to get wrinkly and stuff, and she's putting on weight. I think I will still want to be attractive, that will always be important.

In explaining how reduced physical activity would affect the appearance of their bodies, Pamela's and Vicky's comments echoed Halliwell and 
Dittmar's (2003) observations. They proposed that the most negative aspect of ageing for women is its impact on appearance, which is not surprising when the surfaces of the body symbolise the self (Shilling 2003), and older women in western societies are desexualised and receive negative comments about their appearance (Blaikie I999). Vicky viewed the prospect of ageing as 'not that wonderful', expressing the young athletes' belief that the biological changes of a female ageing body will be experienced socially, not least in terms of looking and feeling less desirable to others.

As with Pamela's comments, Vicky's extract referred to the contradiction between her preferred self (i.e. feeling good and not being hung up on cosmetic-type things), and the expected 'reality' of middle age, as interpreted from her narrative map of her middle-aged mother (i.e. being wrinkly, overweight and image-conscious). Although Vicky hoped to be content with the appearance of her middle-aged body, the narrative map suggested that this is unlikely. Her comments also provide insights into her understanding and reaction to stereotypes about embodiment at different stages of the life course. To Vicky, the idea of being 3 o years-old was clearly so remote as to be virtually unimaginable, and she believed that by that age her current concerns about her body would have long been abandoned ('maybe I won't be bothered at all about my body when I'm 30'). In the references to the narrative map of her mother, however, she realised that her body would still matter. The personification of ageing stereotypes through the narrative maps derived from known individuals, and the ways in which this process challenges or changes the ageist stereotypes presented to young people, warrants further research.

\section{Grandparents and narrative maps of old age}

For the young athletes involved in this study, narrative maps of old age were provided by their grandparents, and these informed their perceptions of the later stages of ageing and of being 'old'. When asked to describe what the term 'being old' meant to her, Pauline, a 20-year-old member of the university basketball squad, replied by describing her grandfather's lifestyle:

I just don't think that you do anything when you're 6o. What do old people do with their time? They just sit in their chairs; that's what my granddad does. He came to live with us when my grandma died. He just sits in his chair, reads the newspaper, watches TV, and goes to bed really early. ... He goes and plays bowls, which is really good ... but bowls! (laughs). How could that [game] satisfy you? It certainly wouldn't satisfy me, but it doesn't seem like there's much more to do.

Pauline compared old age with the anticipated hectic lifestyle of middle age, and envisaged a lifestyle that was slow, repetitive and boring. 
Similarly, when explaining how he would like to be in old age, a I9-yearold competitive cross-country runner and member of the university athletics club, Tim, said:

I don't want to be an old man sat in a chair at a retirement home with other old people, literally just letting the days tick past; I just think that's horrible. My grandpa, when he was old, he couldn't do things for himself ... it just seemed really sad. You'd go to see him and you'd walk in ... it was a great big lounge with all of the chairs around the outside. Each old person had their own chair and it was like [the room had] one TV, magazines and stuff. And everyone was asleep all of the time. It just seemed so mundane. If you weren't in there (the lounge), you were in your room and in there it's just your bed and your TV. It's kind of inevitable that it is going to happen unless you are going to live with your kids, but I wouldn't want to ever get like my grandpa.

Tim drew upon a narrative map that he had fashioned about his grandfather's body and routines, and expected that 'being old' implied being 'bored' and 'dependent', for then the 'days tick pass' and you 'can't do things for yourself'. The prospect of this experience was both feared ('I just think that's horrible') and unavoidable ('it's kind of inevitable that it's going to happen'), and contributed to Tim's negative perception of personal ageing. Similar social implications of the ageing body (e.g. living a 'mundane' existence) were elements of all the participants' responses, but there were also gender differences.

\section{Gendered stories in the perceptions of old age}

For the young male athletes, the perceptions of self-ageing were tied to the anticipated loss of control over a once disciplined body, as they had observed had been their grandfathers' experience. For example, John, aged I9 years and whose life was dominated by playing hockey at international competition level explained:

I just don't want people doing things for me, I don't want people washing me and taking me to the toilet and things, it just seems so undignified. That's what I don't like about it [old age], that's what's so scary, but you can't help it as well, you can't stop it. My granddad has a carer come to his house, I think it's only like for an hour in the morning and at night and stuff, I'm not sure, but I'd just hate that, having someone else get you undressed, wash you.

Similarly, 27-year-old Jamie who, before university had played international rugby, remarked:

I think the biggest concern for me [in old age] would be not being able to control my faculties. Like if I couldn't go to the toilet myself, I wouldn't want somebody to look after me or I wouldn't want to be fed or anything like that. ... My granddad was in a home before he died because he couldn't cope by himself and it was really sad. My main worry is just being dependent on someone, because I'm so 
independent now; I'm fit and strong. My worry would be to lose all control of that, to lose control of the body, which you used to have control over; really, that would be my biggest concern. I wouldn't really want to rely on people in that way.

In line with the observations made by Halliwell and Dittmar (2003), the young male athletes perceived growing old as having a negative impact on the physical capabilities of the body. Using the narrative maps that they constructed from the experiences of their grandfathers, they expected 'old age' to bring a complete loss of their current embodied identity as an athlete, which for years they had carefully and painstakingly constructed around having an able, fit, strong, independent and disciplined body. In short, 'being old' would be the opposite of their current selves and way of living, and they were acutely aware of both the biological and social dimensions. According to Twigg (2003), needing someone to care for your body is an erosion of one's personhood and adult status, and it heightens feelings of vulnerability; moreover, sometimes the younger and stronger helper dominates the relationship. Such outcomes appeared to inform the men's pre-presentations of being old, for they anticipated and feared several identity dilemmas associated with becoming 'uncontrollable' and 'dependent'.

The female athletes, in contrast, were primarily concerned with the changes in physical appearance that old age would bring. Like the young men, however, such changes conflicted with their current embodied status, i.e. having a youthful, toned and performing body. When Laura, aged 20 years and a keen pentathlete, was asked to describe what 'old age' meant to her, she referred to the experiences of her grandmother. Many of her comments were about the physical appearance of her grandmother's 'old' body:

My nan, her face is just so wrinkly, it's like she hasn't got any eyelids, because it's just wrinkles (laughs). And she hasn't got ... like, she's really flat-chested now. She was telling me how embarrassing it was when she was in hospital and they put a heartrate monitor-strap around her. She says there's just nothing there, just saggy skin (laughs). I just don't like the thought of being old; you're just wrinkly and your skin sags. I guess as well it's because you're used to having sort of toned-skin and things, and then you look and there are like wrinkles; and not being able to look in the mirror like you can now, and think, well, I used to be like this and why aren't I still? Why don't I still look like this? Even if, like, I'm working to get my body into shape, why isn't it happening, kind of thing?

Likewise, Pauline spoke vividly about the changed appearance of the body in old age:

I just can't imagine it. I see photos of my nan when she was like 20 or whatever, and the change and just the appearance, it's amazing. It's just so different; you'd hardly know it was the same person. Now, she's really tiny and she hasn't got any 
muscle on her or anything, even though she eats well and she's as active as she can be, I suppose. ... She's changed so much, like her hair going grey and losing muscle and things, and having problems being able to get around. It's quite scary-compared to when she was younger, she was, like, more curvaceous she's so different now. Hopefully I will be a skinny old lady like my nan rather than a fat old lady.

Along with the other young female athletes, Pauline, when referring to the exterior signs of change in her grandmother's body, saw symbolic significance for her own body. The narrative map of old age derived from her grandmother provided the pre-presentations of her preferred (i.e. mobile and skinny old lady) and feared (i.e. immobile and fat old lady) older selves. Clearly, aspects of appearance play a large part in framing the female athlete's perceptions of self-ageing.

\section{Discussion and conclusions}

According to Shilling (I997: 65), any satisfactory analysis of human embodiment requires 'an appreciation of how our fleshy physicality is moulded by social as well as "natural" processes. In this context, the human body is important not only because it provides us with the basic ability to live, but also because it shapes our identities and structures our interventions in, and classifications of, the world'. The findings of this study are congruent with these views, and provide case examples of how the biological and material ageing body is experienced and understood by young athletes, a group of people for whom body and appearance are particularly important.

One important context that shaped the young athletes' perceptions of self-ageing was the family. The bodies of parents and grandparents and how they functioned in time and space provided a narrative map of their possible futures. The maps were gendered, with the men anticipating middle age as a hectic time of life when, as with their fathers, the time available for physical activity would be constricted and rescheduled to weekends, and the women more simply anticipating that the available time will be reduced, with negative consequences for their appearance and bodies. Such gender differences in the narrative maps projected into those for old age. The women's maps featured the loss of control over, or ability to maintain, a toned, shapely, performing and attractive body, while the men's maps were more centred on the demise of a highly disciplined body, the erosion of physical capabilities, and a foreboding sense of increased vulnerability and dependence on others to care for them. 
Given these contrasting anticipations, and in a culture that, on the one hand, celebrates the physical and performance excellence of the bodies that they currently possessed and experienced the world through and, on the other hand, surrounds them with gerontophobic images, it is not surprising that the participants, like young people in general, viewed growing older as a process of physical and mental decline and perceived it in entirely negative terms (Neikrug 2003; Öberg 2003). Of course it is likely that the socialisation of young athletes, or the priorities and value of the sporting subculture that valorises and demands a disciplined, controlled, predictable and performing body, intensifies their fears of ageing and the attached negativity. Their concern about the performance capacities of the body is accentuated, as well as closely monitored by themselves and their peers. The young athletes in our study were highly sensitised to the biological dimensions of ageing, and their summary view was that it would be a process of inevitable decline.

As Turner (I995) noted, individual features of the ageing body (e.g. greying hair, changed skin-tone and decreased mobility, muscular mass and performance) become the subject of social observations and inter-personal monitoring, and the corporeal transformations become a crucial index of the passage of time: 'an individual experiences the process of ageing in relation to the maturation of their body, and also in relation to their collective generational body-image' (I995: 255). Societies, and particularly some subcultures, use socially-constructed age-classification to order and control the meanings of the changes which time brings to the material body. This particularly applies to the moral and aesthetic significance given to change in the external surfaces of the body, and within the sporting subculture to the visible (or observable) performance indicators and outcomes. If this is the case, young athletes may be particularly vulnerable to the socio-biological dynamics of our responses to ageing.

The development of a strong athletic identity (the degree to which an individual identifies with the athlete's role) may lead an individual to interpret any personal change in terms of its implications for their athletic functioning (Brewer, Van Raalte and Linder ig93; Sparkes i996, i998, 2004). On the positive side, the benefits of a strong athletic identity include powerful senses of self-identity, purpose, performance and achievement, and a raised likelihood of keeping up physical exercise in later life. On the other hand, a strong athletic identity, like those tied to any individual performance ability (e.g. musician), has risks associated with career and lifecourse transitions, as at the end of a playing or competitive career. The risk of emotional disturbance at such transitions may be increased if an athlete dedicates so much time to their sport that they compromise their 
readiness for other careers and life-styles. Such 'role engulfment' and 'premature identity foreclosure' can create the conditions for a crisis when the athlete 'retires', and might underlie very negative stereotypes of old age and older people, ageist attitudes, and even extreme gerontophobia or irrational fears about growing old. If this is the case, then questions are raised about the ways in which the pervasiveness and socio-dynamics of ageism in western societies shape the discourse, attitudes and relationships of athletes immersed in sporting subcultures. Do they foster the ridicule of older bodies that are still young but 'past their peak' in performance terms, and does this contribute to the marginalisation of older people? (Phoenix and Sparkes 2006b).

Such speculations and questions call for further research. We need a better understanding of how young athletes draw upon personallyconstructed narrative maps to anticipate change in their bodies, capabilities and appearance. What are the circumstances and conditions that instigate change or, just as importantly, prevent change? For this purpose, longitudinal data would be particularly valuable, as would interviews with older family members on their roles in the family and about their own lifecourse. This study has also shown that several gendered issues mediate perceptions of ageing and old age. When these questions are addressed, our understanding of the family as a key arena for the embodied projection and inscription of ageing narratives will be greatly enhanced. We hope that this article stimulates further work in this area and encourages social gerontologists to give more attention to the experiences of young athletes as they age.

\section{References}

Blaikie, A. 1999. Images of Ageing. Cambridge University Press, Cambridge.

Bornat, J., Dimmock, B., Jones, D. and Peace, S. 200o. Researching the implications of family change for older people. In Chamberlayne, P., Bornat, J. and Wengraf, T. (eds), The Turn to Biographical Methods in Social Sciences: Comparative Issues and Examples. Routledge, London, 244-96.

Brewer, B. W., Van Raalte, J. and Linder, D. E. I993. Athletic identity: Hercules' muscle or Achilles' heel? International Fournal of Sport Psychology, 24, 237-54.

Drew, L. M. and Silverstein, M. 2004. Inter-generational role investments of greatgrandparents: consequences for psychological well-being. Ageing \& Society, 24, I, 95-I I I.

Ex, C. T. G. M. and Janssens, M. A. M. 20oo. Young females images of motherhood. Sex Roles, 43, II/12, 865-9o.

Faircloth, C. A. 2003. Introduction. In Faircloth, C. A. (ed.), Aging Bodies, Images and Everyday Experiences. Altamira, Walnut Creek, California, I-29.

Featherstone, M. and Wernick, A. I995. Introduction. In Featherstone, M. and Wernick, A. (eds), Images of Aging. Routledge, London, I-I5.

Furman, F. K. 1997. Facing the Mirror: Older Women and Beauty Shop Culture. Routledge, London. 
Gergen, K. J. and Gergen, M. M. 1988. Narrative and the self as relationship. Advances in Experimental Social Psychology, 21, 17-56.

Halliwell, E. and Dittmar, H. 2003. A qualitative investigation of women's and men's body image concerns and their attitudes toward aging. Sex Roles, 49, II/I2, 675-84.

Hequembourg, A. and Brallier, S. 2005. Gendered stories of parental caregiving among siblings. Fournal of Aging Studies, r 9, 53-7r.

Hockey, J. and James, A. 2003. Social Identities Across the Life Course. Palgrave Macmillan, London.

Hodgetts, D., Chamberlain, K. and Bassett, G. 2003. Between television and the audience: negotiating representations of ageing. Health: An Interdisciplinary Fournal for the Social Study of Health, Illness and Medicine, 7, 4, 417-38.

Holstein, J. and Gubrium, J. 200o. The Self We Live By. Oxford University Press, New York.

Hyde, V. and Gibbs, I. I993. A very special relationship: granddaughters' perceptions of grandmothers. Ageing \& Society, I 3, 83-96.

Jeffreys, M. 1997. Inter-generational relationships: an autobiographical perspective. In Jameson, A., Harper, S. and Victor, C. (eds), Critical Approaches to Ageing and Later Life. Open University Press, Buckingham, 77-89.

Laz, C. 2003. Age embodied. Fournal of Aging Studies, I 7, 503-19.

Lieblich, A., Tuval-Mashiach, R. and Zilber, T. 1998. Narrative Research: Reading, Analysis and Interpretation. Sage, London.

Markus, H. and Nurius, P. ig86. Possible selves. American Psychologist, 41, 954-69.

McAdams, D. P. I996. Narrating the self in adulthood. In Birren, J. E., Kenyon, G. M., Ruth, J.-E., Schroots, J. J. F. and Svensson, T. (eds), Aging and Biography: Explorations in Adult Development. Springer Publishing Company, New York, I3 ${ }^{\mathrm{I}}-48$.

Neikrug, S. 2003. Worrying about frightening old age. Aging and Mental Health, 7, 326-33.

Newton, T. 2003. Truly embodied sociology: marrying the social and the biological? Sociological Review, 4, 20-42.

Öberg, P. 2003. Images versus experience of the aging body. In Faircloth, C. (ed.), Aging Bodies: Images and Everyday Experiences. Altamira, Walnut Creek, California, I03-39.

Phoenix, G., Faulkner, G. and Sparkes, A. 2005. Athletic identity and self-ageing: the dilemma of exclusivity. Psychology of Sport and Exercise, 6, 3, 335-48.

Phoenix, C. and Sparkes, A. C. $2006 a$. Young athletic bodies and narrative maps of aging. Journal of Aging Studies, forthcoming.

Phoenix, C. and Sparkes, A. C. 2006 b. Sporting bodies, narrative maps of ageing and young team athletes: an analysis of possible selves. Sport, Education and Society, forthcoming.

Pollner, M. and Stein, S. 1996. Narrative mapping of social worlds: the voice of experience in Alcoholics Anonymous. Symbolic Interaction, 1 9, 3, 203-23.

Schröder-Butterfill, E. 2004. Inter-generational family support provided by older people in Indonesia. Ageing \& Society, 24, 4, 497-530.

Sheehan, N. W. and Donorfio, L. M. I999. Efforts to create meaning in the relationship between aging mothers and their caregiving daughters: a qualitative study of caregiving. Journal of Aging Studies, I 3, 2, г6 - -76 .

Shenk, D. 200I. Intergenerational family relationships of older women in central Minnesota. Ageing \& Society, 2 I, 59I-603.

Shilling, G. 1997. The body and difference. In Woodward, K. (ed.), Identity and Difference. Sage, London, 63-120.

Shilling, C. 2003. The Body and Social Theory. Second edition, Sage, London.

Sparkes, A. C. I996. The fatal flaw: a narrative of the fragile body-self. Qualitative Inquiry, 2, 4, 463-94.

Sparkes, A. C. 1998. Athletic identity: an Achilles heel to the survival of self. Qualitative Health Research, 8, 5, 644-64. 


\section{Cassandra Phoenix and Andrew C. Sparkes}

Sparkes, A. C. 2004. Bodies, narratives, selves, and autobiography: the example of Lance Armstrong. Fournal of Sport and Social Issues, 28, 397-428.

Turner, B. 1995. Aging and identity: some reflections on the somatization of the self. In Featherstone, M. and Wernick, A. (eds), Images of Aging. Routledge, London, 245-6o.

Twigg, J. 2003. The body and bathing: help with personal care at home. In Faircloth, C. A. (ed.), Aging Bodies, Images and Everyday Experiences. Altamira, Walnut Creek, California, I43-69.

Twigg, J. 2004. The body, gender, and age: feminist insights in social gerontology. Fournal of Aging Studies, 18, 59-73.

Upton, R. L. and Han, S. S. 2003. Maternity and its discontents: 'getting the body back' after pregnancy. Fournal of Contemporary Ethnography, 32, 6, 670-92.

Wenger, G. C. and Burholt, V. 200I. Differences over time in older people's relationships with children, grandchildren, nieces and nephews in rural North Wales. Ageing E्E Society, 2I, $567-90$.

Williams, S. 2003. Medicine and The Body. Sage, London.

Address for correspondence:

Accepted 28 January 2006

Cassandra Phoenix, Qualitative Research Unit, School of Sport and

Health Sciences, St Luke's Campus, Exeter University, Exeter,

Devon EXI $2 \mathrm{LU}$, UK.

E-mail: H.G.Phoenix@exeter.ac.uk 